\title{
ANALISIS EFISIENSI ALAT PENYULINGAN MINYAK NILAM (PATCHOULY OIL ) DENGAN PROSES KAPASITAS KERING 30 KG PER JAM
}

\author{
INDRIYANI \\ Universitas Sang Bumi Ruwa Jurai \\ indryinthan@gmail.com
}

\section{Abstrak}

\begin{abstract}
Minyak Nilam (patchouly oil).) merupakan tanaman penghasil minyak atsiri/minyak nilam. Minyak nilam merupakan salah satu komoditas ekspor minyak atsiri lainnya. Minyak nilam ini menyumbang sekitar 50\% dari total nilai ekspor minyak atsiri. Untuk mendapatkan minyak nilam proses produksi dilakukan dengan cara penyulingan. Proses penyulingan ini dilakukan untuk memisahkan air/minyak yang terkandung didalam nilam. Dalam proses penyulingan minyak nilam terdiri dari bagian yang utuma adalah bahan yang digunakan, bahan bakar, dapur, ruang pemanas dan ruang pendingin. Pembakaran merupakan suatu proses pensenyawaan antara unsur-unsur bahan bakar dengan zat asam (berasal dari udara) disertai dengan keluarnya kalor. Kalor yang dilepaskan ini akan sebanding dengan banyaknya unsurunsur yang terkandung dalam bahan bakar. Setiap unsur mengeluarkan kalor yang berbeda. Dalam perencanaan ini yang digunakan sebagai bahan bakar adalah kayu dengan berat jenis 0,70\% dengan komposisi kimia sebagai berikut: $\quad C=38,90-53,50 \% ; \quad H=5,80-6.30 \% . O=40,30-44,60 \%$. Perencanaan unit penyulingan minyak nilam ini, proses dimulai dari perhitungan perpindahan panas dari bahan bakar dapur, ruang. Pemanas dan ruang pendingin (kondesor) dalam satu jam produksi. Dalam hal ini bahan baku yang digunakan adalah nilam dengan kapasitas $30 \mathrm{~kg} / \mathrm{jam}$ nilam kering yang masih mengandung kadar air/minyak $30 \%$ standar dari nilam siap untuk diproses. Penggunaan bahan bakar disesuaikan dengan jenis bahan bakar yang digunakan. Bentuk dapur harus efisien agar panas yang dihasilkan dapat maksimal. Ruang pemanas di sesuaikan dengan kapasitas produksi.
\end{abstract}

\section{Abstract}

Nilam Oil (patchouly oil) is a plant producing essential oil / patchouly oil (patchouly oil). Patchouli oil is one of the other essential oil export commodities. This patchouli oil contributes about $50 \%$ of the total value of volatile oil exports. To obtain patchouli oil the production process is done by distillation. The process of distillation is done to separate the water / oil contained in the patchouli. In the process of patchouli oil refining consists of 
the utmost part is the materials used, fuel, kitchen, space heater and cooling room. Combustion is a process of compounding between fuel elements with acidic substances (coming from the air) accompanied by the release of heat. This released heat will be proportional to the number of elements contained in the fuel. Each element emits different heat. In this plan used as fuel is wood with a specific gravity of $0.70 \%$ with the chemical composition as follows: $C$ $=38.90-53.50 \% ; H=5.80-6.30 \% . O=40.30-44.60 \%$. Planning this patchouli oil distillation unit, the process starts from the calculation of heat transfer from the kitchen, space fuel. Heating and cooling (condenser) in one hour of production. In this case the raw material used is patchouli with a capacity of $30 \mathrm{~kg} / \mathrm{hour}$ dry patchouli that still contains the moisture content / oil $30 \%$ standard of patchouli ready for processing.

Keywords : distillation tools, processing capacity, combustion, refining, space heater, cooling room

\section{PENDAHULUAN}

Minyak nilam merupakan salah satu jenis minyak atsiri yang memiliki permintaan cukup cerah. Penggunaan terbesar minyak nilam sebagai bahan kosmetik pengikat wangi parfum. Pasar dunia saat ini membutuhkan sebesar 1.200 - 1.400 ton minyak nilam rata-rata setahun dengan kecenderungan yang terus meningkat. Kebutuhan tersebut $80-90 \%$ dipasok Indonesia. Pada saat itu produk minyak nilam di Indonesia lebih dikenal dengan sebutan Javapatchouli, karena mayoritas ekspor minyak tersebut melalui pelabuhan Tanjung Priok (Rukmana, 2014).

Minyak nilam ini menyumbang sekitar $50 \%$ dari total nilai ekspor minyak atsiri. Minyak nilam merupakan salah satu komoditas ekspor minyak atsiri lainnya. Nilam (Pengotemen coblin bent, family habitat), merupakan tanaman penghasil minyak atsiri/minyak nilam (Patchouly oil). Untuk mendapatkan minyak nilam, proses produksi dilakukan dengan cara penyulingan. Proses penyulingan ini dilakukan untuk memisahkan air/minyak 
yang terkandung didalam nilam. Dalam proses penyulingan minyak nilam bagian yang utuma adalah bahan yang digunakan, bahan bakar dapur, ruang pemanas dan ruang pendingin.

Salah satu penghasil minyak daun nilam yang ada di Jawa Timur adalah para petani yang tersebar di kecamatan Dongko kabupaten Trenggalek. Namun demikian jumlah itu belum bisa memenuhi kebutuhan ekspor minyak daun nilam. Permasalahan yang sering timbul disebabkan oleh kurangnya informasi teknologi dan belum adanya standarisasi metode kerja penyulingan minyak nilam, sehingga minyak nilam yang dihasilkan masih bermutu rendah. Pengeringan langsung di bawah sinar matahari menyebabkan sebagian minyak atsiri turut menguap dan pengeringan yang terlalu cepat menyebabkan daun rapuh dan sulit untuk disuling. Sebaliknya, jika pengeringan terlalu lambat, daun akan menjadi lembab dan muncul bau yang tidak enak, sehingga mutu minyak yang dihasilkan menurun (Kardinan, 2015).

Minyak nilam yang baik sebaiknya tidak tercampur dengan bahan lain (murni) karena bila tercampur dengan bahan lain akan mempengaruhi aroma minyaknya dan standar mutunya akan turun. Oleh karena itu, minyak nilam harus memenuhi syarat dalam perdagangan dan industri. Standar mutu minyak nilam belum ada keseragaman untuk seluruh dunia. Masing-masing negara baik eksportir maupun importir mempunyai standar mutu minyak nilam sendiri-sendiri. Standar mutu minyak nilam menurut ISO 3757:2002 yaitu kadar kandungan patchouli alcohol (selanjutnya dibaca: PA) antara 27 \% - $35 \%$. Dikatakan dapat menghasilkan kualitas eksport yakni kadar patchouli alcohol tidak kurang dari 30\% (septa-ayatullah.blogspot.com). Pada penelitian ini dari data patchouli alcohol yang diambil dilapangan, tercatat bahwa semua data kurang dari $30 \%$. Meskipun masih dalam batas standar 
mutu menurut ISO 3757:2002, akan tetapi hasil yang diperoleh masih kurang baik. Dengan mengetahui data tersebut, perlu adanya perbaikan proses untuk menghasilkan minyak dengan mutu yang tinggi serta dapat memenuhi standar mutu eksport minyak nilam. Maka peneliti menerapkan konsep Six Sigma guna meningkatkan kualitas hasil produksi penyulingan minyak nilam.

\section{LANDASAN TEORI}

Teknik penyulingan minyak atsiri yang selama ini diusahakan para petani, masih dilakukan secara sederhana dan belum menggunakan teknik penyulingan secara baik dan benar. Selain itu, penanganan hasil setelah produksi belum dilakukan secara maksimal, seperti pemisahan minyak setelah penyulingan, wadah yang digunakan, penyimpanan yang tidak benar, maka akan terjadi proses-proses yang tidak diinginkan, yaitu oksidasi, hidrolisa ataupun polimerisasi. Alat suling tradisional dengan tangki bekas drum minyak menjadi salah satu penyebab, dimana ion logam seperti magnesium, besi, mangan, tembaga, plumbum, dan seng dapat terlarut di dalam minyak.Biasanya minyak yang dihasilkan akan terlihat lebih gelap dan berwarna kehitaman atau sedikit kehijauan akibat kontaminasi dari logam $\mathrm{Fe}$ dan $\mathrm{Cu}$. Hal ini akan berpengaruh terhadap sifat fisika kimia minyak (Tri Marwati dan Hernani, 2016).

Pada penyulingan minyak nilam cara yang dilakukan adalah dengan penguapan nilam dalam ruang pemanas. Sistem penyulingan minyak nilam ini merupakan sebuah proses produksi dari nilam kering yang masih mengandung kadar air $15 \%$ sampai standar nilam siap diproses. Di dalam ruang pemanas yang berbentuk tangki air dan nilam dipisah dengan pembatas pada posisi nilam diatas air. Pembatas antara air dan nilam berbentuk lubanglubang yang berfungsi untuk tempat aliran uap panas dari air kenilam, 
kemudian nilam yang mendapat panas dari uap air akan menguap, dengan masih bercampur dengan uap air, uap nilam mengalir menuju ruang pendingin untuk dirubah kembali dari uap menjadi tetes air/minyak. Dalam penyulingan minyak nilam ini yang akan menjadi bahasan adalah: bahan bakar dapur, ruang pemanas dan ruang pendingin (kondensor).

Tabel 1. Nilai Kalor Pembakaran

\begin{tabular}{|c|c|c|c|c|}
\hline \multirow{2}{*}{ Macam Zat } & \multicolumn{2}{|c|}{ Npa (Kkal) } & \multicolumn{2}{|c|}{ Npb (Kkal) } \\
\hline & Per kg bb & Per $\mathbf{m}^{3}$ bb & Per kg bb & Per $\mathbf{m}^{3}$ bb \\
\hline $\mathrm{C}$ & 33915 & & 33915 & \\
\hline $\mathrm{S}$ & 10468 & & 10468 & \\
\hline $\mathrm{H} 2$ & 144033 & 12770 & 121423 & 12016 \\
\hline
\end{tabular}

Nilai pembakaran atas adalah nilai tertinggi atau highest heating value dari hasil pembakaran dengan unsur-unsur didalam bahan bakar sempurna.

$\mathrm{Npa}=33915 . \mathrm{C}+144033\left(\mathrm{H}-\frac{0}{8}\right)+10468 \mathrm{~S} \mathrm{Kkal} / \mathrm{jam}$.

Nilai pembakaran dibawah adalah nilai pembakaran terendah lowest heating value dari hasil pembakaran dengan unsur-unsur kimia didalam bahan bakar tidak sempurna.

$\mathrm{Npb}=33915 . \mathrm{C}+121423\left(\mathrm{H}-\frac{0}{8}\right)+10468 \mathrm{~S} \mathrm{Kkal} / \mathrm{jam} \mathrm{S}-2512(\mathrm{~W})$

\subsection{Pemakaian Bahan Bakar}

Pemakaian bahan bakar adalah jumlah bahan bakar yang digunakan dalam persatuan waktu. Dapat dihitung sebagai berikut:

$$
\text { B } \frac{Q}{N p b x n k} \mathrm{Kg} / \mathrm{jam}
$$

Dimana:

B = Banyak bahan bakar yang digunakan $\mathrm{kg} / \mathrm{jam}$

$\mathrm{Q}=$ = Panas yang dibutuhkan untuk menghasilkan uap kkal/jam

$\mathrm{Npb}=$ Nilai pembakaran bawah kkal/jam

$\mathrm{Nk}=$ Efisiensi ketel $(\%)$ 


\subsection{Kebutuhan Udara Pembakaran}

Pemakaian udara untuk membakar bahan bakar dalam dapur sangat diperlukan. Cara yang bisa digunakan untuk memasukkan udara adalah dengan sistem penarikan. Dalam hal ini dapat di lakukan dengan penarikan alam maupun penarikan buatan. Jumlah udara pembakaran yang diperlukan untuk membakar bahan bakar yang sempurna dapat dihitung berdasarkan susunan kimia bahan bakar.

$$
\text { But }=115 . \mathrm{C}-34.5(\mathrm{H})+4.37 \mathrm{~kg} \cdot \mathrm{udara} / \mathrm{kg} \cdot \mathrm{bb}
$$

\subsection{Analisa Efisiensi Kabel}

Peran yang dihasilkan dai pembakaran $100 \%$ ini akan dikurangi dengan kerugian panas yang berhuna untuk pemanasan.

$$
\mathrm{n} \mathrm{k}=\frac{Q}{B \cdot N p b} \%
$$

Dimana:

$\mathrm{B}$ = Banyak Bahan bakar yang digunakan $\mathrm{kg} / \mathrm{jam}$

$\mathrm{Q}$ = Panas yang dibutuhkan untuk menghasilkan uap Kkal/jam

$\mathrm{Npb}=$ Nilai pembakaran bawah Kkal/jam

$\mathrm{Nk}=$ Efisiensi Ketel $(\%)$

\section{METODOLOGI PENELITIAN}

\subsection{Jenis Penelitian}

Penelitian ini merupakan penelitian sesungguhnya (true experiment), hal ini berdasarkan pada pemikiran bahwa penelitian dilakukan untuk meneliti 
kemungkinan efisiensi penggunaan alat-alat penyulingan yang digunakan dan mencoba mendesain ulang peralatan penyulingan yang dimungkinkan lebih efektif dan efisien. Sehingga memungkinkan peningkatan penghasilan bagi pengelola penyulingan minyak nilam tersebut. Hasil analisis efisiensi alat penyulingan nilam ini akan direkomendasikan ke pihak perusahaan sebagai alternatif sarana produksi.

\subsection{Variabel-Variabel}

Adapun variabel-variabel yang digunakan meliputi variabel bebas, variabel terikat dan variabel terkendali. Jika terdapat variabel tersebut namun tidak mempunyai pengaruh berat atau utama, maka variable tersebut termasuk dalam variabel terkendali.

\subsection{Variabel Bahan Bakar}

Bahan bakar merupakan bahan untuk menghasilkan panas yang diperlukan untuk membentuk uap diperoleh dengan pembakaran bahan bakar. Pembakaran merupakan suatu proses pensenyawaan antara unsur-unsur bahan bakar dengan zat asam (berasal dari udara) disertai dengan keluarnya kalor. Pembakaran dari bahan bakar mengandung unsur antara lain: Zat arang atau karbon $(\mathrm{C})$, hidrogen $(\mathrm{H})$, Zat asam atau oksigen $(\mathrm{O})$, zat lemas atau nitrogen $(\mathrm{N})$, belerang $(\mathrm{S})$, Abu dan Air yang semuanya terkait dalam satu senyawa kimia.

\subsection{Variabel Alat Penyulingan}

Variabel ini merupakan kelengkapan alat penyulingan yang dilakukan sebagai proses produksi, diantaranya: ketel penyulingan, alat pendingin, bak pemisah dan ketel uap. 


\subsection{Variabel Dapur}

Dapur suatu ruangan dimana terjadi proses pembakaran yang mampu melakukan pembakaran bahan bakar, untuk menghasilkan panas yang sempurna sehingga kualitas penyulingan maksimal.

\subsection{Variabel Terkendali}

Sistem penyulingan merupakan mekanisme dan prosedural penyulingan, serta penggunaan jenis dan mekanisme sirkulasi bakar. Apabila mekanisme dan prosedural serta jenis bebeda dari standar maka akan mempengaruhi dalam proses penyulingan

\subsection{Desain Penelitian}

Penelitian ini dilakukan di Laboratorium Teknik Mesin Fakultas Teknik Universitas Sang Bumi Ruwa Jurai yang beralamat di Jalan Imam Bonjol No. 468 Langkapura Bandar Lampung 35154. Penelitian dilaksanakan dari tanggal 26 April 2017 - 26 Oktober 2017.

\subsection{Metode Pengumpulan Data}

Beberapa metode yang digunakan dalam penelitian penyulingan manyak nilam. adalah sebagai berikut:

a. Metode Observasi, yaitu melalui pengamatan dan pencatatan secara langsung dan sistematis terhadap masalah yang mempengaruhi penyulingan miyak nilam.

b. Metode Quesioner, yaitu data-data yang didapat melalui Tanya jawab langsung dengan pihak yang mengerti paham dan kompeten dalam masalah penyulingan minyak nilam. 


\subsection{Sumber Data}

Data yang akan menjadi dasar penelitian pada sistem pengapian ini didapat dari berbagai sumber, yaitu antara lain:

a. Data dari lapangan, dimana pada data ini merupakan data kongkrit atau nyata dilapangan yang menunjukkan permasalahan yang sebenarnya terjadi pada setiap waktu, setiap tempat dimana saja dan kapan saja. Data dari lapangan ini juga sebagai tolok ukur permasalahan di lapangan yang menjadi bahan pemikiran dari persoalan yang terjadi pada sistem penyulingan minyak nilam.

b. Data dari pustaka yang berkaitan dengan obyek permasalahan yang diangkat, dimana data diambil dari literatur literature yang memiliki keterkaitan.

\section{HASIL DAN PEMBAHASAN}

Analisis efisiensi alat penyulingan minyak nilam ini dimulai dari proses perhitungan perpindahan panas dari bahan bakar dapur ruang pemanas dan ruang pendingin (kondensor) dalam satu jam produksi. Dalam hal ini bahan baku yang digunakan adalah nilam dengan kapasitas $30 \mathrm{~kg} / \mathrm{jam}$ nilam kering yang masih mengandung kadar air/minyak $30 \%$ standar dari nilam siap untuk diproses. Secara teoritis berat air yang dihasilkan oleh daun nilam sama dengan kadar air minyak dalam daun kali banyaknya daun/kg 0,15 x 304,5 $\mathrm{kg}$.

Mengatasi rendahnya kualitas yang berwarna gelap akibatkontaminasi ion logam, minyak dapat dilakukan pengkelatan, namun dengan metode adsorpsi dengan menggunakan bentonit leb menguntungkanPemurnian minyak 
cengkeh dengan bentonit sebagai penyerap logam terbaik ketimbang arang aktifdan zeolit Pemurnianminyak cengkeh dengan arang aktif $5 \%$ dan bentonit $5 \%$. Hasilnya dengan bentonitkejernihan minyak dapat mencapai $75,58 \%$ sedangkan dengan arangaktif hanya 2,7 \%. Secara fisik warnaminyak yang dimurnikan denganbentonit menjadi cokelat mudasedangkan dengan arang aktiftetap hitam (Tri Marwati dan Hernani, 2016).

Minyak nilam mengandung senyawa patchouli alkohol yang merupakan penyusun utama dalam minyak nilam, dan kadarnya mencapai $50-60 \%$. Patchouli alkohol merupakan senyawa yang tidak larut dalam air, larut dalam alkohol, eter atau pelarut organik yang lain. Mempunyai titik didih 280,37 ${ }^{\circ} \mathrm{C}$ dan kristal yang terbentuk memiliki titik lelah $56{ }^{\circ} \mathrm{C}$ (Yanyan F.N, Ahmad Zainuddin dan Dadan Sumiarsa, 2014).

Nilai pembakaran atas (Npa) dapat dihitung dengan menggunakan persamaan:

$$
\begin{aligned}
\mathrm{Npa} & =33915 . \mathrm{C}+144033\left(\mathrm{H}-\frac{0}{8}\right)+10468 . \mathrm{S} \\
& =33915.0,53+144033\left(0,63-\frac{0}{8}\right)+10468.0 \\
& =19414,33 \mathrm{kjoule} / \mathrm{kg} \\
& =4636,8 \mathrm{kkal} / \mathrm{kg}
\end{aligned}
$$

Nilai pembakaran bawah (Npb) dapat dihitung dengan persamaan:

$$
\begin{aligned}
\mathrm{Npb} & =33915 . \mathrm{C}+121423\left(\mathrm{H}-\frac{0}{8}\right)+10468-2512(\mathrm{~W}) \\
& =33915.0,15+121423\left(0,63-\frac{0}{8}\right)+10468.0-2512(0,09) \\
& =19327,299 \mathrm{kjoule} / \mathrm{kg} \\
& =4616,025 \mathrm{kkal} / \mathrm{Kg}
\end{aligned}
$$




\section{Pemakaian Bahan Bakar}

Pemakaian Bahan bakar persatuan waktu dapat dihitung dengan menggunakan persamaan:

$$
\begin{aligned}
\mathrm{B} & =\frac{Q}{N p n \times n k} \\
\mathrm{~B} & =\frac{18776,75}{4616,02 \times 0,8} \\
\mathrm{~B} & =5,08 \mathrm{~kg} / \mathrm{jam}
\end{aligned}
$$

\section{Dapur}

Dapur yang diterapkan oleh Penyulingan Minyak Nilam Adiluwih Gedungtataan berbentuk silinder yang terbuat dari batu bata tahan api dengan bagian dalamnya dilapisi plat besi, Diameter $=0,50 \mathrm{~m}$ dan tinggi $0,50 \mathrm{~m}$. Dapur ini disesuaikan dengan kondisi yang ada di lapangan.

\section{Kapasitas Dapur}

Jumlah kalor yang dihasilkan oleh bahan bakar di dalam ruang dapur persatuan waktu dapat dihitung dengan persamaan:

$$
\begin{aligned}
\mathrm{Kd} & =\mathrm{Bb} \times \mathrm{Npb} \\
& =5,08 \times 4616,02 \\
& =23449,37 \mathrm{kkal} / \mathrm{jam}
\end{aligned}
$$

\section{Volume Ruang Bakar}

$$
\begin{aligned}
\mathrm{V} & =\mathrm{n} \cdot \mathrm{r}^{2} \cdot \mathrm{t} \\
\mathrm{V} & =3,14 \cdot 0 \cdot 30 \cdot 0,5 \\
\mathrm{~V} & =0,14,13 \mathrm{~m}
\end{aligned}
$$

\section{Ruang Pemanas}

Dalam hal ini ruang pemanas yang terbentuk tangki berfungsi sebagai tempat untuk pemrosesan air dan nilam. Air yang digunakan sebangak $25 \mathrm{~kg}$ 
berfungsi untuk menghantar panas kedalam daun nilam sebangak $30 \mathrm{~kg}$ dengan kandungan air $15 \%$ dengan diketahui temperatur awal $30{ }^{\circ} \mathrm{C}$ dan Temperatur akhir $1.953^{\circ} \mathrm{C}$ dan tekanan $15 \mathrm{~atm}$.

\section{Panas yang Dibutuhkan Untuk Menghasilkan Uap}

Jumlah panas yang dibutuhkan untuk menghasilkan uap dapat dihitung dengan persamaan:

$$
\begin{aligned}
\mathrm{Q} & =29.5 \times 636.8 \\
& =18776,75 \mathrm{kkal} / \mathrm{jam}
\end{aligned}
$$

\section{Panas yang Dibutuhkan Daun Nilam}

Panas yang dibutuhkan adalah sama dengan panas yang digunakan untuk pemanasan air. Jadi, jumlah total uap semua yang dihasilkan, dengan ketentuan $\mathrm{Ba}=\mathrm{Bu}$ berat air yang sebenarnya sama dengan uap yang dihasilkan $(\mathrm{kg})$ adalah:

$$
\mathrm{B}_{\text {tot }}=\mathrm{B}_{\mathrm{ua}}-\mathrm{B}_{\mathrm{un}}
$$

Dimana:

$$
\begin{aligned}
& \mathrm{B}_{\mathrm{tot}} \quad \text { = Jumlah banyak uap semuanya dengan satuan } \mathrm{kg} / \mathrm{jam} \\
& \mathrm{B}_{\mathrm{ua}} \quad \text { = Banyaknya uap air dengan satuan } \mathrm{kg} / \mathrm{Jam} \\
& \mathrm{B}_{\mathrm{un}} \quad \text { = Banyaknya uap nilam dengan satuan } \mathrm{kg} / \mathrm{jam}
\end{aligned}
$$

Maka:

$$
\begin{aligned}
\mathrm{B}_{\mathrm{tot}} & =\mathrm{B}_{\mathrm{ua}}-\mathrm{B}_{\mathrm{un}} \\
& =25+4,5 \\
& =29,5 \mathrm{~kg} / \mathrm{jam}
\end{aligned}
$$




\section{Pendinginan}

Pendinginan adalah proses perpindahan suatu masa atau zat dari temperatur yang panas ke temperatur yaming lebih dingin dengan mengalirkan zat tersebut malalui pipa ke tempat bak pendingin, dalam hal ini yang digunakan adalah air sebagai zat pendingin dengan temperatur $30^{\circ} \mathrm{C}$.

\section{Panas yang Dilepaskan Uap}

Panas yang dilepaskan terjadi saat Pendinginan dari uap yang bertemperatur tinggi ke tempat yang bertemperatur rendah, malalui pipa menuju ruang pendingin (kondensasi) dapat dihitung dengan

$$
\mathrm{Q} \quad=\mathrm{m} \times \mathrm{c}\left(\mathrm{T}_{1}-\mathrm{T}_{2}\right) \mathrm{kkal} / \mathrm{jam}
$$

Dimana:

$\mathrm{Q}=$ = Panas yang dilepaskan uap dengan satuan kkal/jam.

$\mathrm{m}=$ masa/berat uap yang dihasilkan $29,5 \mathrm{~kg}$ uap

c $\quad=$ Kalor sepesifik air dengan satuan $\mathrm{kkal} / \mathrm{kg}{ }^{0} \mathrm{C}$

$\Delta \mathrm{T}=$ Temperatur uap ${ }^{\circ} \mathrm{C}$ Temparatur air pendingin ${ }^{\circ} \mathrm{C}$

$$
=1983{ }^{\circ} \mathrm{C}-30{ }^{\circ} \mathrm{C}=168.3{ }^{\circ} \mathrm{C}
$$

Maka:

$$
\begin{aligned}
\mathrm{Q} & =29.5 .(1) .(198.3-30) \\
& =4964,85 \mathrm{kkal} / \mathrm{jam}
\end{aligned}
$$

\section{Jumlah Air Pendingin yang Diperlukan}

Jumlah air yang dibutuhkan untuk pendinginan dengan kondisi pipa di dalam air pendingin, dapat dihitung dengan menggunakan persamaan:

$$
\mathrm{W}=\frac{Q}{c(\Delta T)} \mathrm{kkal} / \mathrm{jam}
$$


Dimana:

$\mathrm{W}=$ Jumlah air yang dibutuhkan dengan satuan $\mathrm{kg} / \mathrm{jam}$

$\mathrm{Q}$ = Panas yang dibutuhkan untuk menghasilkan uap dengan satuan $\mathrm{kkal} / \mathrm{jam}$

$\mathrm{C}=$ Kalor sepesifik air dengan satuan $\mathrm{kkal} / \mathrm{kg}^{\circ} \mathrm{C}$

$\Delta T=$ Temperatur air pendingin ${ }^{\circ} \mathrm{C}=\mathrm{T}-\mathrm{Tr} .{ }^{\circ} \mathrm{C}$

Maka:

$$
\begin{aligned}
\mathrm{W} & =\frac{Q 18776,75}{168,3} \\
\mathrm{~W} & =115,59 \mathrm{kkal} / \mathrm{jam}
\end{aligned}
$$

\section{KESIMPULAN}

Analisis efisiensi alat penyulingan minyak nilam menggunakan peralatan sederhana dengan tanpa mengabaikan fungsi dan kegunaannya. Secara kuantitatif hasil perhitungan pada unit penyulingan minyak nilam adalah: Bahan bakar

Jenis bahan bakar

Nilai pembakaran atas

Nilai pembakaran bawah

Pemakaian bahan bakar

Dapur

Kapasitas dapur

Volume

Ruang pemana 0

Temperatur awal

Temperatur akhir

Tekanan

Air yang digunakan
: kayu jati

: $4636.8 \mathrm{kkal} / \mathrm{kg}$

: 4616,025 kkal/kg

: $5,08 \mathrm{~kg} / \mathrm{jam}$
: 23449,37 kkal/jam

: $0,143 \mathrm{~m}$

: $30^{\circ} \mathrm{C}$

: $1983{ }^{\circ} \mathrm{C}$

: $15 \mathrm{~atm}$

: $25 \mathrm{~kg}$ air 
Bahan baku : $30 \mathrm{~kg}$ daun nilam

Panas yang dibutuhkan $\quad: 18776.75 \mathrm{kkal} / \mathrm{jam}$

Pendingin

Panas yang dilepaskan uap $\quad: 4964,85 \mathrm{kkal} / \mathrm{jam}$

Jumlah air yang dibutuhkan $: 1,59 \mathrm{~kg} / \mathrm{jam}$

\section{DAFTAR PUSTAKA}

Ayatullah, Septa, 2012, Resume dari Penelitian "Kualitas Minyak Nilam sebagai Tanaman Sela pada Areal Lahan Hutan Rakyat di Desa Cibojong, http://septa-ayatullah.blogspot.com/2009/04/resume-daripenelitian-kualitas-minyak.html, (diakses pada 27 Januari 2012).

Budianto, A. \& R, Lilis, 2012, "Ekstraksi Minyak Nilam Menggunakan Destilasi Uap", Jurnal IPTEK, Vol.5, No. 1: 66-71.

Dale H. Besterfield, 2014, Quality Control, Prentictice - Hall International, Inc, New Jersey.

Kardinan, Agus, 2015, Tanaman Penghasil Minyak Atsiri, Komoditas Wangi Penuh Potensi, PT Agro Media Pustaka, Tangerang.

Montgomery, Douglas C., 2012, Pengantar Pengendalian Kualitas Statistik, Gajah Mada University Press, Yogyakarta.

Nurlelasari, 2013, Peningkatan Kadar Patchouli Alkohol Pada Minyak Nilam Melalui Teknik Kultur Jaringan, Universitas Padjajaran, Bandung.

Nuryani,Y., 2014, Karakteristik Minyak Nilam Hasil Fusi Protoplas Antara Nilam Aceh dengan Nilam Jawa, http://minyakatsiriindonesia.wordpress.com/atsiri-nilam/yang-nuryani. (diakses Pada 27 Januari 2014).

Rukmana, Rahmat, 2014, NILAM, Prospek Agribisnis dan Teknik Budi Daya, KANISIUS. Yogykarta.

Tri Marwati dan Hernani, 2016. Peningkatan Mutu Minyak Atsiri melalui Proses Pemurnian, Balai Besar Litbang Pascapanen Pertanian, Disampaikan pada Konferensi Nasional Minyak Atsiri. 
Yanyan F.N, Ahmad Zainuddin dan Dadan Sumiarsa, 2014. Peningkatan Kadar Patchouli Alkohol dalam Minyak Nilam dan Denuatisasi Komponen Minornya. diakses 22 Januari 2014 (http;//minyak atsiriindonesiawordpress.com/atsirinilam/yanyan-f.n-dkk). 